Int. J. Electrochem. Sci., 15 (2020) $8096-8107$

International Journal of

ELECTROCHEMICAL

SCIENCE

www.electrochemsci.org

\title{
All-solid-state Potentiometric Biosensors Based on Electropolymerized Poly(3,4-ethylenedioxythiophene) as Solid Contact for Acetylcholine Determination in Artificial Cerebrospinal Fluid
}

\author{
Cheng He ${ }^{1, *}$, Guang $\mathrm{Li}^{2}$, You Wang ${ }^{2}$, Wujie Zhou ${ }^{1}$ \\ ${ }^{1}$ School of Information and Electronic Engineering, Zhejiang University of Science and Technology, \\ Hangzhou 310023, P. R. China \\ ${ }^{2}$ State Key Laboratory of Industrial Control Technology, College of Control Science and Engineering, \\ Zhejiang University, Hangzhou 310027, P. R. China \\ *E-mail: hecheng@zust.edu.cn
}

doi: $10.20964 / 2020.08 .66$

Received: 3 April 2020 / Accepted: 26 May 2020 / Published: 10 July 2020

\begin{abstract}
All-solid-state ion-selective electrodes are a feasible method to realize the determination of neurotransmitters. Herein, an all-solid-state potentiometric acetylcholine biosensor was investigated. Poly(3,4-ethylenedioxythiophene) doped with poly(sodium 4-styrenesulfonate) as solid contact was electropolymerized on a gold disk covered with an acetylcholine selective membrane containing heptakis(2,3,6-tri-O-methyl)- $\beta$-cyclodextrin as ionophore. The biosensor could work stably within a pH range from 6.5 to 8.5. The optimized acetylcholine biosensor had a good linear correlation over an acetylcholine concentration range of $10^{-5} \mathrm{M}$ to $10^{-2} \mathrm{M}$ with a slope of $58.2 \pm 1.2 \mathrm{mV} /$ decade and the detection limit was $6.01 \pm 1.02 \mu \mathrm{M}$. The interference resistance, repeatability and stability were evaluated. The biosensor was also applied to detect the dynamic change of acetylcholine in artificial cerebrospinal fluid. The results showed that the newly developed biosensor had high sensitivity, a rapid response and a long lifetime. The technology is promising for fabricating acetylcholine biosensors with various suitable structures to satisfy the requirements of neurophysiological researches.
\end{abstract}

Keywords: Acetylcholine biosensor; All-solid-state; Ion-selective electrode; Artificial cerebrospinal fluid

\section{FULL TEXT}

(C) 2020 The Authors. Published by ESG (www.electrochemsci.org). This article is an open access article distributed under the terms and conditions of the Creative Commons Attribution license (http://creativecommons.org/licenses/by/4.0/). 